\title{
Agronomic
} Journal

\section{EFICIÊNCIA DE FUNGICIDA SISTÊMICO COM MULTISSÍTIOS PARA O CONTROLE DA FERRUGEM ASIÁTICA DA SOJA}

\author{
EFFICIENCY OF SYSTEMIC FUNGICIDE WITH MULTISITES FOR THE CONTROL OF ASIAN SOY RUST
}

\author{
Douglas de Deus de Sá ${ }^{1}$; Bruna Camila Rangel ${ }^{1}$; Iara Alves Gonçalves ${ }^{1}$; Fabrício Pereira de Araújo ${ }^{1}$;
} José Eduardo Barbosa de Souza².

${ }^{1}$ Engenheiro Agrônomo, Faculdade Evangélica de Goianésia;

${ }^{2}$ Mestre, Engenheiro Agrônomo, professor da Faculdade Evangélica de Goianésia.

\begin{tabular}{l} 
Info \\
\hline Recebido: $10 / 2020$ \\
Publicado: $10 / 2020$ \\
ISSN: $2595-6906$ \\
DOI: \\
\hline Palavras-Chave \\
Phakopsora pachyhizi, AACPD, \\
severidade. \\
Keywords: \\
Phakopsora pachyhizi, AACPD, \\
severity
\end{tabular}

\begin{abstract}
Resumo
A cultura da soja vem mantendo a tendência de crescimento na área cultivada e, nesta safra 2018-2019, a estimativa aponta para crescimento de 2,3\% em relação ao ciclo passado, produzindo 120,9 milhões de toneladas. A ferrugem asiática é uma doença causada pelo fungo basidiomiceto Phakopsora pachyrhizi, originário da Austrália, essa doença chegou ao Brasil em 2001. Por apresentar um alto potencial destrutivo para a cultura da soja, em todos os países onde foi detectada, Considerada atualmente o principal problema a ser combatido pelos sojicultores brasileiros, a ferrugem asiática tem sido alvo de exaustivas tentativas de controle, as condições ambientais favorecem a ocorrência da doença. As avaliações da incidência de P. Pachyrhizi foram realizadas em: estádio V4; V6; R1/R2; R1/R2 + 14 dias; R1/R2 +
\end{abstract}

28 dias; R1/R2 + 42 dias e R1/R2 + 49 dias, para a produção da área abaixo da curva de progresso dos dados para severidade (AACPD) da P. pachyrhizi na cultura da soja. Na colheita (R9) foi avaliado a média de altura de planta, utilizando quatro plantas por parcela, a área colhida foi de $4 \mathrm{~m} 2$. Após a colheita as plantas foram trilhadas manualmente e estimado a produtividade em kg.ha-1 com umidade de $13 \%$ no grão, e posteriormente estimando o peso de 1.000 grãos. As avaliações da porcentagem de severidade foram realizadas pela escala diagramática para a ferrugem asiática. Conclui-se que os tratamentos SPM + Difere, SPM + Previnil 720, SPM + Manfil 800 WD, SPM + Fezan Gold, SPM + Eleve, SPM + Nillus, SPM + Bravonil 720 sc refletiu de modo semelhante na produtividade da cultura. Em relação ao peso de mil grãos todos os tratamentos foram semelhantes estatisticamente sendo superiores apenas a testemunha sem controle. As aplicações de SPM + Bravonil 500 sc, SPM + Unizeb Gold, e SPM + Previnil 720 sc, apresentaram menor índice de severidade da doença AACPD.

\footnotetext{
Abstract

Soybean cultivation has been maintaining the growing trend in the cultivated area and, in this 2018-2019 crop, the estimate points to growth of $2.3 \%$ over the past cycle, producing 120.9 million tons. Asian rust is a disease caused by the basidiomycete fungus Phakopsora pachyrhizi, originating from Australia, this disease came to Brazil in 2001. Because it has a high destructive potential for soybean cultivation in all countries where it was detected. Currently considered the main problem. To be fought by Brazilian soybean farmers, Asian rust has been the target of exhaustive control attempts, environmental conditions favor the occurrence of the disease. P. pachyrhizi incidence assessments were performed at: stage V4; V6; R1 / R2; R1 / R2 + 14 days; R1 / R2 + 28 days; R1 / R2 + 42 days and R1 / R2 + 49 days for yield of the area under the P. pachyrhizi severity data progress curve (AACPD) in soybean. At harvest (R9) the average plant height was evaluated, using four plants per plot, the harvested area was $4 \mathrm{~m} 2$. After harvesting the plants were manually tracked and estimated yield in kg.ha-1 with $13 \%$ moisture in the grain, and then estimating the weight of 1,000 grains. The severity percentage evaluations were performed by the diagrammatic scale for Asian rust. It was concluded that the treatments SPM + Differ, SPM + Previnil 720, SPM + Manfil 800 WD, SPM + Fezan Gold, SPM + Eleve, SPM + Nillus, SPM + Bravonil 720 sc reflected similarly on crop yield. Regarding the weight of one thousand grains, all treatments were statistically similar, being superior only to the control without control. The applications of SPM + Bravonil 500 sc, SPM + Unizeb Gold, and SPM + Previnil 720 sc presented lower AACPD disease severity index.
} 


\section{INTRODUÇÃO}

A ferrugem asiática é uma doença causada pelo fungo basidiomiceto Phakopsora pachyrbiri, originário da Austrália, essa doença chegou ao Brasil em 2001, e em 2002 esta já estava disseminada em cerca de $60 \%$ de toda a área cultivada do país e 90 $\%$ em 2003, comprometendo a produtividade das lavouras e a rentabilidade do agricultor. As perdas alcançaram cerca de U\$251 milhões na safra de 20012002, e mais de U\$ 1 bilhão na safra 2002/2003 e chegando a 2 bilhões em 2003/2004 (YORINORI, 2005).

Por apresentar um alto potencial destrutivo para a cultura da soja, em todos os países onde foi detectada, considerada atualmente o principal problema a ser combatida pelos sojicultores brasileiros, a ferrugem asiática tem sido alvo de exaustivas tentativas de controle, as condições ambientais favorecem a ocorrência da doença. Mediante as dificuldades de incorporação de resistência em programas de melhoramento, o uso de cultivares tolerante tem se tornado interessante. Essa medida está ligada a uma estratégia de selecionar genótipos com elevado potencial de produção, mesmo estas já atacadas pelo fungo (HARTMAN; MILES; FREDERICK, 2005).

Atualmente, as recomendações de manejo para a ferrugem asiática da soja têm sido baseadas na aplicação de fungicidas protetores em mistura com triazóis, estrobilurinas e carboxamidas. Por apresentar resultados mais satisfatório em relação as outras medidas de controle(ALVES\&JULIATTI, 2018).

Diante das perdas com ferrugem asiática, os fungicidas aplicados de forma preventiva tem se destacado como uma estratégia eficaz no controle desta doença. Pois apresenta um maior período residual e um melhor desempenho do que os outros fungicidas devido à sua aplicação preventiva. (VITTTI et al., 2004).

Os fungicidas multissítio se retratam como um importante mecanismo de combate a resistência de fungos, pois possui ação multissítio de amplo aspectro, ou seja, o produto vai atuar em vários sítios do fungo, o que irá dificultar a possibilidade de resistência destes fungos. Dentre as vantagens apresentadas pelos fungicidas multissítio situa-se a preservação dos princípios ativos, que está perdendo eficiência com o decorrer dos anos, se tornando um retorno considerável devido esse aumento na eficácia desse produto (NOTÍCIAS AGRÍCOLAS, 2016).

Modo de ação dos fungicidas sistêmicos (Unissítios), Os Triazóis Atuam na formação do ergosterol, que é um importante lipídio fúngico para a formação da membrana das células. A ausência desta camada leva ao colapso da célula fúngica (micélio) e à interrupção do crescimento micelial (corpo fúngico). As Estrobilurinas reagem com substâncias lipídicas da superfície da planta apresentando, por isso, um prolongado efeito protetor ao serem lentamente liberadas (ELEVAGRO, 2015).

As Carboxamidas Apresentam efeito inibidor sobre a produção da enzima succinato desidrogenase (SDHI), atuante no Complexo II da cadeia de transporte de elétrons na mitocôndria do fungo, impedindo a oxidação de succinato para fumarato (ELEVAGRO, 2017). Os fungicidas Protetores (Multissítios) Apresentam moléculas fungicidas que agem em diversos pontos do metabolismo do fungo simultaneamente (UPL BRASIL, 2017).

O objetivo deste trabalho foi avaliar o desempenho da mistura de fungicida sistêmico com multissítios para o controle do fungo Phakopsora pachyrbizi na cultura da soja. 


\section{MATERIAL E MÉTODOS}

A presente pesquisa foi realizada na safra 2018/2019, em área experimental da fazenda Vera Cruz Agropecuária Ltda. situada em Goianésia-Go, localizada na Latitude $15^{\circ} 19^{\prime} 03^{\prime \prime} \mathrm{S}$, Longitude $49^{\circ}$ 07' 03" W, com altitude de $640 \mathrm{~m}$, situado no município de Goianésia/GO. O solo da área de implantação do experimento é um solo areno argiloso.

Utilizou-se como delineamento experimental o de blocos casualizados (DBC), com 12 tratamentos e 4 repetições, totalizando 48 parcelas. As unidades experimentais apresentaram 6 linhas de $5 \mathrm{~m}$ de comprimento, com espaçamento de $0,45 \mathrm{~m}$ entre as mesmas.Os tratamentos realizados estão descritos na Tabela 1 .

Tabela 1. Ingrediente ativo (i.a.), produto comercial (p.c.) e dose dos fungicidas nos tratamentos para controle da ferrugemasiática da soja, Goianésia-Go, safra 2018/2019.

\begin{tabular}{|c|c|c|c|c|}
\hline Trat. & I.A. & $\begin{array}{l}\text { Dose I.A. por } \\
\text { g ha-1 }\end{array}$ & P. C. & $\begin{array}{c}\text { Dose } \mathrm{L} \text { ou } \mathrm{kg} \text { pc } \\
\text { ha-1 }\end{array}$ \\
\hline 1 & Testemunha & - & - & - \\
\hline 2 & Ciproconazol - Trifloxistrobina & 25 & Sphere Max & 0,2 \\
\hline 3 & $\begin{array}{c}\text { Ciproconazol - Trifloxistrobina }+ \\
\text { Clorotalonil }\end{array}$ & $25+150$ & $\begin{array}{c}\mathrm{SM}+\text { Previnil } 720 \\
\text { SC }\end{array}$ & 0,2 \\
\hline 4 & $\begin{array}{l}\text { Ciproconazol - Trifloxistrobina } \\
+ \text { Clorotalonil }\end{array}$ & $25+200$ & $\begin{array}{c}\text { SM }+ \text { Bravonil } 500 \\
\text { SC }\end{array}$ & 0,2 \\
\hline 5 & $\begin{array}{l}\text { Ciproconazol - Trifloxistrobina } \\
+ \text { Clorotalonil }\end{array}$ & $25+200$ & SM +Nillus & 0,2 \\
\hline 6 & $\begin{array}{l}\text { Ciproconazol - Trifloxistrobina } \\
\text { +Clorotalonil-Tebuconazol }\end{array}$ & $25+200$ & $\mathrm{SM}+$ Fezan God & 0,2 \\
\hline 7 & $\begin{array}{c}\text { Ciproconazol - Trifloxistrobina }+ \\
\text { Mancozebe }\end{array}$ & $25+150$ & SM +Unizeb Gold & 0,2 \\
\hline 8 & $\begin{array}{c}\text { Ciproconazol - Trifloxistrobina } \\
+ \text { Mancozebe }\end{array}$ & $25+150$ & SM +Eleve & 0,2 \\
\hline 9 & $\begin{array}{c}\text { Ciproconazol - Trifloxistrobina }+ \\
\text { Mancozebe }\end{array}$ & $25+150$ & SM+Manfil $800 \mathrm{WP}$ & 0,2 \\
\hline 10 & $\begin{array}{l}\text { Ciproconazol - Trifloxistrobina } \\
\text { +Equivalente em cobre metálico, } \\
\text { Oxicloreto de cobre }\end{array}$ & $25+50$ & SM+Difere/Status & 0,2 \\
\hline 11 & $\begin{array}{c}\text { Ciproconazol - Trifloxistrobina }+ \\
\text { Equivalente em cobre metálico, } \\
\text { Oxicloreto de cobre }\end{array}$ & $25+100$ & $\mathrm{SM}+$ Reconil & 0,2 \\
\hline 12 & $\begin{array}{c}\text { Ciproconazol - Trifloxistrobina }+ \\
\text { Equivalente em cobre metálico, } \\
\text { Oxicloreto de cobre }\end{array}$ & $25+70$ & $\mathrm{SM}+\mathrm{Recop}$ & 0,2 \\
\hline
\end{tabular}

*Utilização de 0,25\% de óleo mineral Áureo na calda.

*As doses utilizadas foram seguindo orientação descrita na bula dos produtos.

Para a aplicação dos tratamentos foi utilizando bomba costal a base de $\mathrm{CO}_{2}$ (pressão de 40 libras pol ${ }^{-2}$ e pontas T'T 110.03) para o volume de calda proporcional a $150 \mathrm{~L} \mathrm{ha}{ }^{-1}$.Aplicou-se o herbicida glyphosate $\left(2,5 \mathrm{Kg} \mathrm{ha}^{-1}\right)$ e chlorimuron-ethyl (50 $\mathrm{g} \mathrm{ha}^{-1}$ ) para a dessecação pré-plantio. Após esse procedimento esperou-se por um período de 15 dias para que fosse 
viável realizar a semeadura, sendo que está fora realizada no dia 19 de dezembro de 2018, utilizando-se a cultivar de soja BMX CERTA IPRO.

Foi utilizado $100 \mathrm{~kg} \mathrm{ha}^{-1}$ do adubo MAP (1152-00) e $100 \mathrm{~kg}$ ha de KCL à lanço 15 dias após a semeadura, segundo recomendações técnicas para cultura da soja e, baseada na análise de solo. Com relação ao tratamento de sementes, este foi utilizado os fungicidas Derosal Plus + Gaucho na dosagem de $200 \mathrm{~mL} 100 \mathrm{~kg}^{-1}$ semente.

Para o controle de pragas, plantas daninhas e adubações foliares, foram utilizadas conforme o planejamento da empresa Vera Cruz Agropecuária Ltda. para a área comercial. As aplicações dos tratamentos foram: $1^{\mathrm{a}}$ aplicação em R1/R2 (pleno florescimento), $2^{\mathrm{a}}$ aplicação em R1/R2 mais 14 dias; a $3^{\mathrm{a}}$ aplicação em R1/R2 mais 28 dias e a $4^{\mathrm{a}}$ aplicação em R1/R2 mais 42 dias. Consequentemente as avaliações da incidência de $P$. Pachyrhizi foram realizadas em: estádio V4; V6; R1/R2; R1/R2 + 14 dias; R1/R2 + 28 dias; R1/R2 + 42 dias e R1/R2 + 49 dias, para a produção da área abaixo da curva de progresso dos dados para severidade (AACPD) da P. pachyrhizina cultura da soja.
$\mathrm{Na}$ colheita (R9) foi avaliado a média de altura de planta, utilizando quatro plantas por parcela, medindo da base da planta rente ao solo à extremidade. E foram colhidas as duas linhas centrais de cada parcela desprezando-se meio metro de cada lado, a área colhida foi de 3,6 m². Após a colheita as plantas foram trilhadas manualmente e estimado a produtividade em $\mathrm{kg} \cdot \mathrm{ha}^{-1} \mathrm{com}$ umidade (\%) de 13\% no grão, e posteriormente estimando o peso de 1.000 grãos, utilizando balança de precisão Shimadzu, modelo BL320H.

As avaliações da porcentagem de severidade foram realizadas pela escala diagramática para a ferrugem asiática apresentada por Canteri e Godoy (2003). Onde são avaliadas as intensidades em porcentagem (\%) da presença do fungo Phakopsora pakirhizi nas áreas foliares nos dias 01/02/2019 (estádio V4 ), 08/02/2019 (estádio V6 ), 22/02/2019 (estádio R1), 08/03/2019 (estádio R1+15 dias), 22/03/2019 (estádio R1 + 25 dias), 29/03/2019 (estádio R1 + 35 dias), 05/04/2019 (estádio $\mathrm{R}+42$ dias) e 12/04/2019 (estádio R1 + 49 dias), sendo feita visualmente por dois avaliadores.

\section{Escala Diagramática para ferrugem da soja}
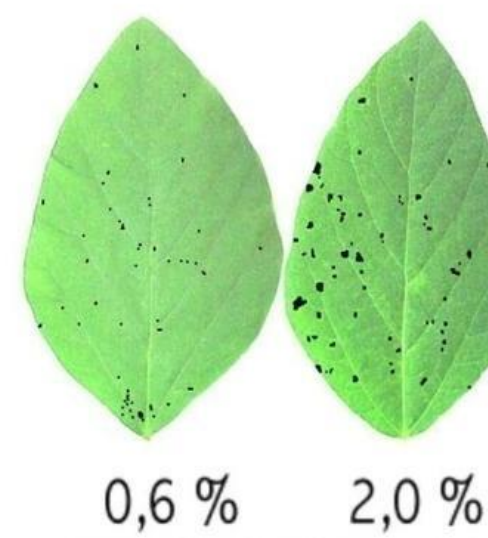
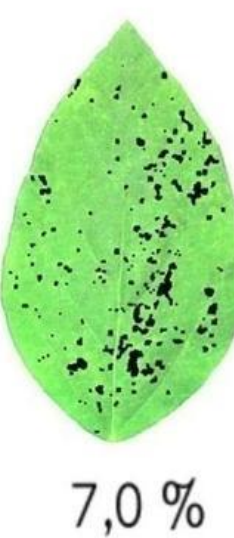
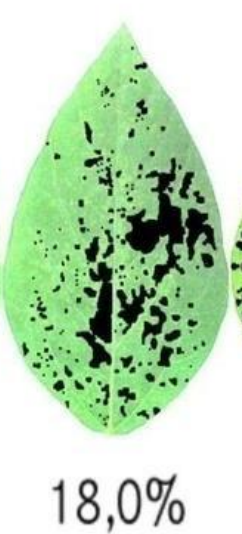
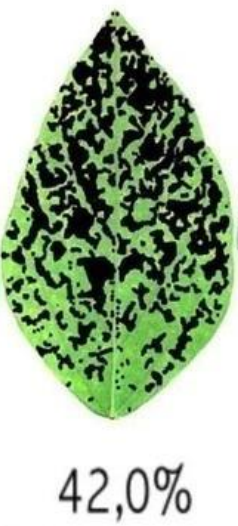

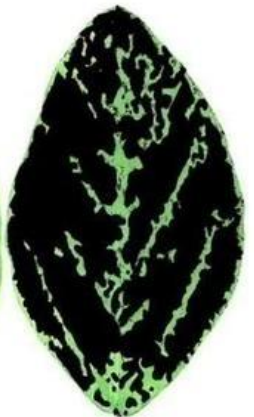

$78,5 \%$

CANTERI M. G. GODOY C. V. Escala diagramática para avaliação da severidade da ferrugem da soja In: XXVI Congresso Paulista de Fitopatologia, 2003, Araras.

Summa Phytopathologica. Botucatu: Grupo Paulista de Fitopatologia, v.29. p.89 - 89. 2003.

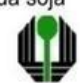
Universidade Embrapa
Estadual de Londrina

Figura 1 - Escala Diagramática para avaliação de severidade da ferrugem asiática da soja (Embrapa, 2019). 
O progresso da doença foi estimado por meio da área abaixo da curva de progresso de doença (AACPD), que foi calculada a partir da curva de progresso da doença, obtidos em cada avaliação, por meio da fórmula abaixo, segundo Shaner e Finnley (1977):

$$
\text { AACPD }=\Sigma_{i=1}^{n-1}\left[\left(Y_{i}+Y_{i+1}\right) / 2 \times\left(T_{i+1}-T_{i}\right)\right] \text {, onde: }
$$

Yi = Proporção da doença na i-ésima observação;

$\mathrm{Ti}$ = tempo (dias) na i-ésima observação e;

$\mathrm{N}=$ número total de observações.

A AACPD foi padronizada dividindo-se o valor da área abaixo da curva de progresso pela duração de tempo total $\left(\mathrm{t}_{\mathrm{n}}-\mathrm{t}_{1}\right)$ da epidemia para comparar epidemias de diferentes durações. O software ASSISTAT (SILVA E AZEVEDO, 2016). Foi tilizado para obtenção dos dados de AACPD, quando ocorreu a diferença significativa, as médias foram comparadas pelo teste de Scott
Knott a 5\% de significância.

\section{RESULTADOS E DISCUSSÃO}

Os resultados obtidos na avaliação do peso de mil grãos (P1000G $\left.-\mathrm{g}^{-1}\right)$, conforme figura 2, não diferiram estatisticamente entre os tratamentos químicos, no entanto esses tratamentos estatisticamente foram superiores a Testemunha.

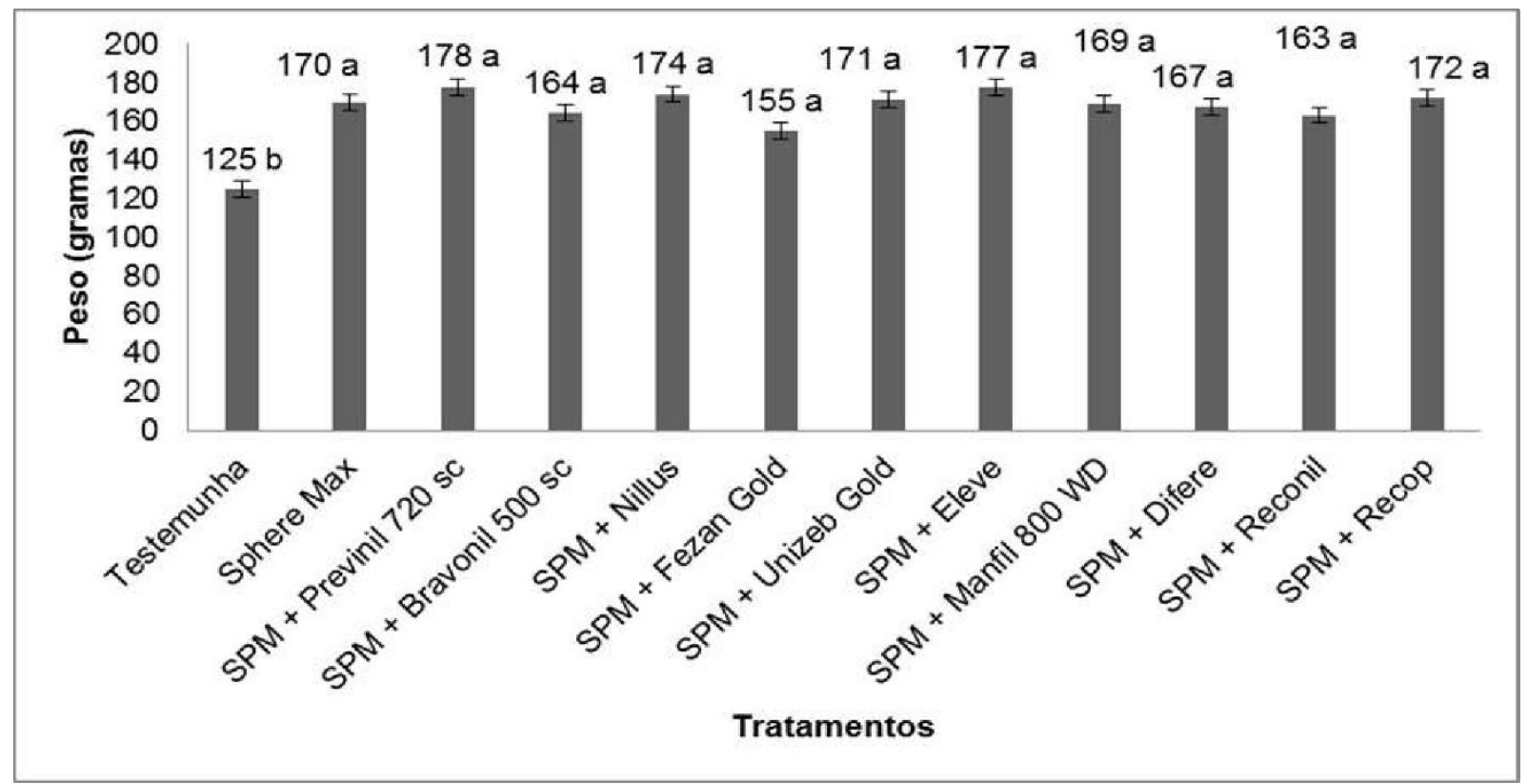

Figura 2 - Peso médio de mil grãos (P1000G $-\mathrm{g}^{-1}$ ) da cultivar BMX CERTA IPRO. No experimento da fazenda Vera Cruz Agropecuária Ltda., Goianésia, GO, safra 2018/2019. Médias seguidas da mesma letra não diferem estatisticamente entre sí pelo teste de Scott-Knott a 5\% de probabilidade.

A variação do tratamento (T3) SPM + Previnil 720 sc, obteve valor maior em peso em gramas, seguido em ordem decrescente por (T8) SPM + Eleve, (T5) SPM + Nillus, (T12) SPM +
Recop, (T7) SPM + Unizeb Gold, (T2) Sphere Max, (T9) SPM + Manfil $800 \mathrm{WD}$, (T10) SPM + Difere, (T4) SPM + Bravonil 500 sc, (T11) SPM + Reconil, (T6) SPM + Fezan Gold e testemunha sem 
tratamento (T1), Sendo a única que obteve diferença significativa conforme resultado estatístico, sendo esta inferior aos demais tratamentos.

Todos os fatores empregados se diferiram da testemunha e o peso variou de 155 gramas SPM + Fezan Gold, até 178 gramas SPM + Previnil 720 sc. Segundo o trabalho de Dinnys et al. (2010) que avaliou os efeito dos fungicidas no controle da ferrugem da soja, com relação a produtividade de grãos, peso de mil grãos, todos os tratamentos foram semelhantes entre sí e superiores a testemunha sem controle corroborando com este trabalho. Para avaliação da curva de progressão da doença (AACPD), conforme figura 3, a variação da severidade foi de 1.119 à 2.430 .

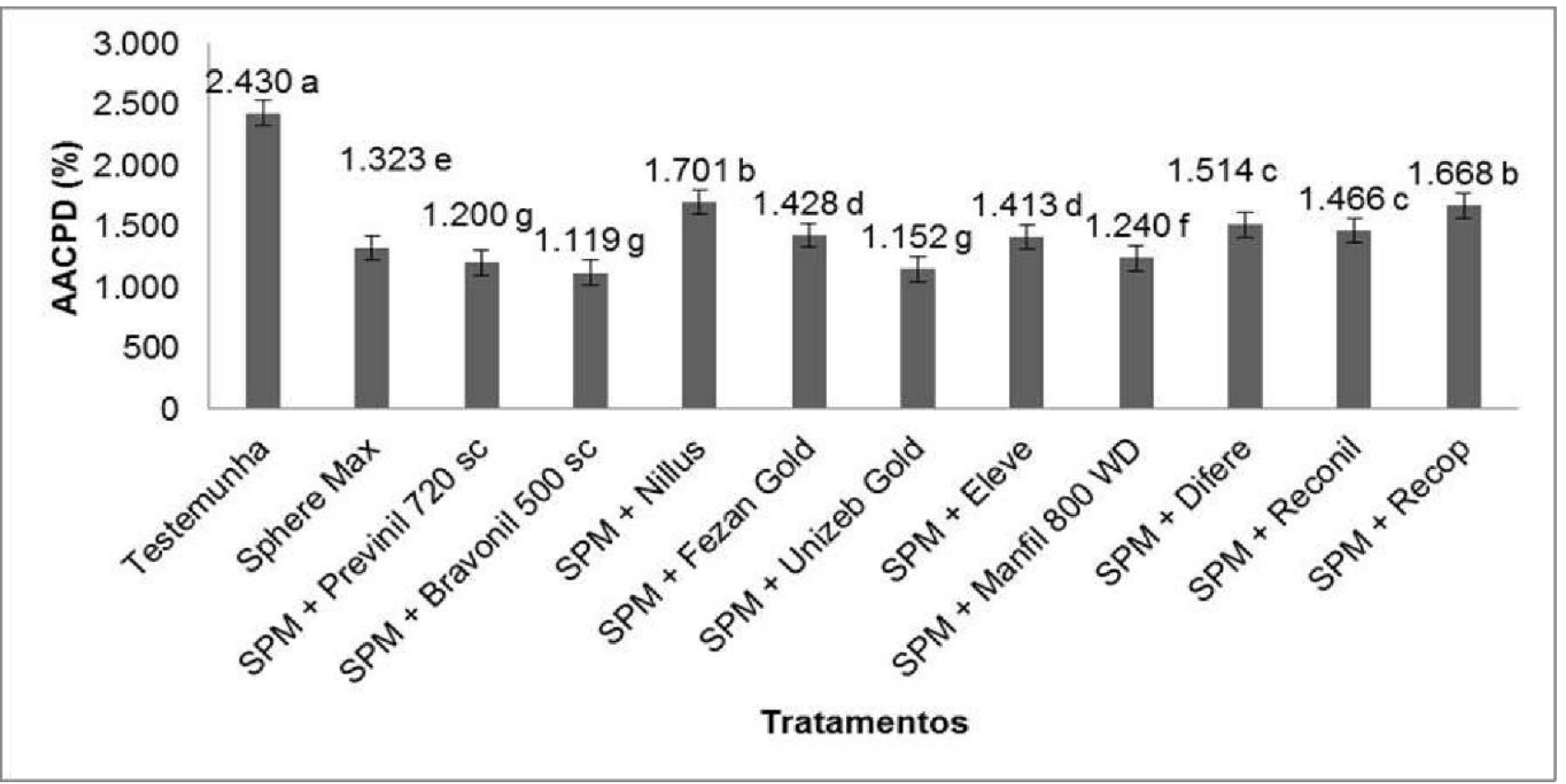

Figura 3 - Curva AACPD da ferrugem asiática sobre a cultivar BMX CERTA IPRO, no experimento da fazenda Vera Cruz Agropecuária Ltda., Goianésia, GO, safra 2018/2019.

Médias seguidas da mesma letra não diferem estatisticamente entre sí pelo teste de Scott-Knott a 5\% de probabilidade

O presente trabalho demonstrou que os tratamentos químicos para a ferrugem asiática diminuiram significativamente o desenvolvimento desta, uma vez que o índice da severidade da doença encontrado na avaliação realizada entre os fungicidas químicos foram significativamente inferiores ao resultado obtido na avaliação da Testemunha.

Ao avaliar a AACPD, com base na severidade média nas plantas, verifica-se que, os fungicidas que apresentaram menor progresso da ferrugem asiática em relação a testemunha, com eficácia superior a 52\% foram SPM + Bravonil 500 SC, SPM + Previnil 720 SC, e SPM + Unizeb Gold,
Sendo seguido por Manfil 800 WD com eficácia de 49\%. O fungicida Sphere Max apresentou eficácia de 46\%. Os fungicidas Eleve e Fezan Gold, apresentaram eficácia de $42 \%$ e $41 \%$ Respectivamente. Os fungicidas Reconil e Difere apresentou eficácia 40\% e 38\% respectivamente. Os fungicidas Nillus, e Recop apresentaram os maiores valores de progresso da doença, com eficácia inferior a $31 \%$.

O trabalho de CARLIN et al (2019), na avaliação de fungicidas multissítios no controle da ferrugem-asiática da soja. Considerando a AACPD, que representa todas as avaliações da severidade, observou-se que todos os tratamentos contribuíram 
significativamente para a redução da AACPD. Sendo também os menores valores foram proporcionados pelos tratamentos Previnil 720 sc e Bravonil corroborando com este trabalho.

Para avaliação da produtividade média, conforme a figura 4 , todos os tratamentos químicos apresentaram produtividade superior à Testemunha. Os tratamentos SPM + Previnil 720
SC, SPM + Bravonil 500 SC, SPM + Nillus, SPM + Fezan Gold, SPM + Eleve, SPM + Manfil 800 WD e SPM + Difere, foram superiores estatisticamente aos demais tratamentos. Os tratamentos: SPM + Recop; SPM + Reconil; SPM + Unizeb Gold e Sphere Max foram superiores somente à Testemunha sem controle.

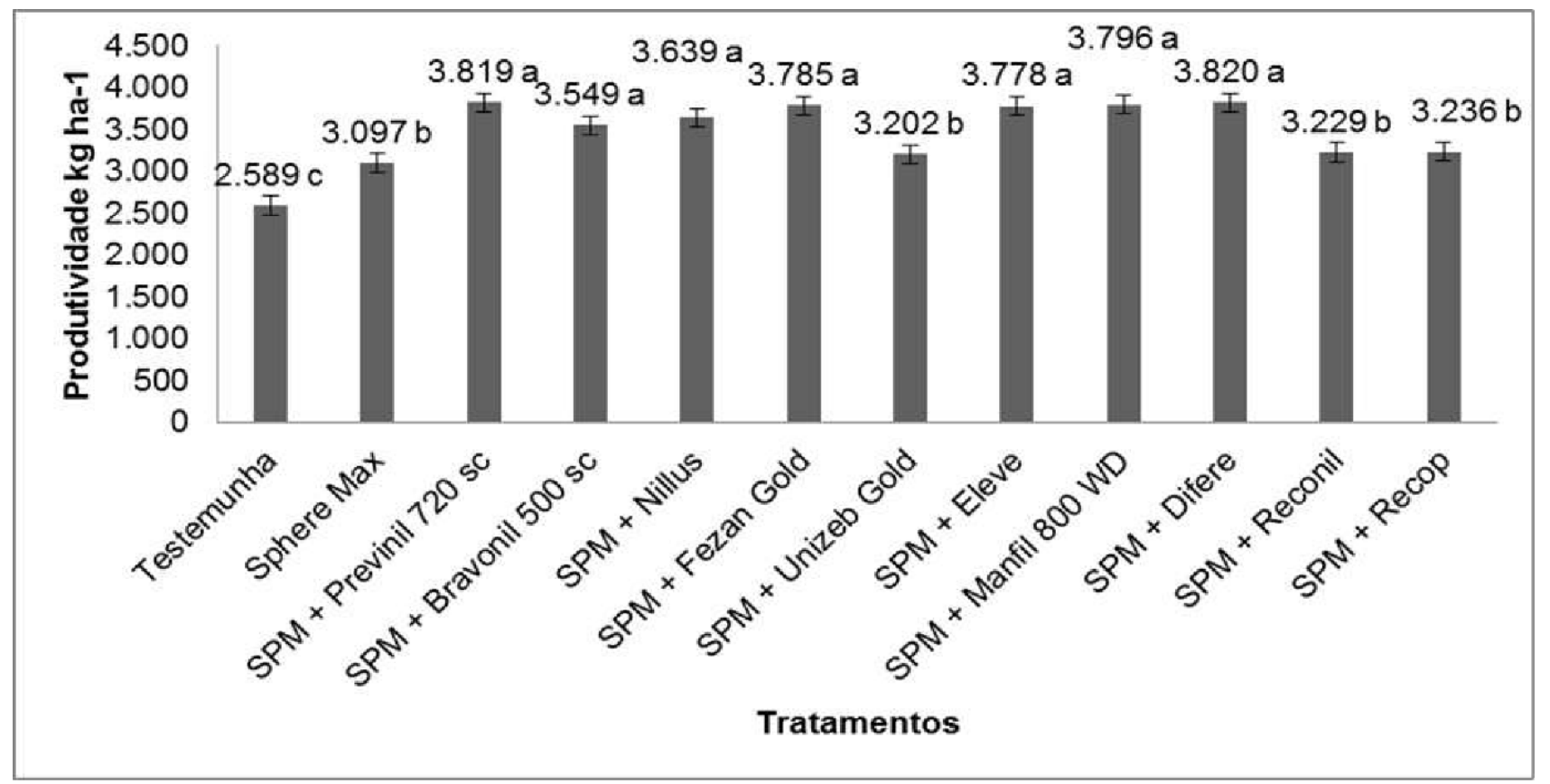

Figura 4 - Produtividade média $\left(\mathrm{kg} \mathrm{ha}^{-1}\right)$ da cultivar BMX CERTA IPRO, no experimento da fazenda Vera Cruz Agropecuária Ltda., Goianésia, GO, safra 2018/2019. Médias seguidas da mesma letra não diferem estatisticamente entre sí pelo teste de Scott-Knott a 5\% de probabilidade.

A produtividade do experimento foi superiores estatisticamente para os tratamentos SPM + Previnil 720 sc, SPM + Bravonil 500 sc, SPM + Nillus, SPM + Fezan Gold, SPM + Eleve, SPM + Manfil 800 WD, SPM + Difere.

O tratamento SPM + Difere, obteve a produtividade de $3.820 \mathrm{~kg} \mathrm{ha}^{-1}$, tendo uma diferença superior à Testemunha de $1.231 \mathrm{~kg} \mathrm{ha}^{-1}$, ou seja, SPM + Difere apresentou um ganho de 32,22\%, e para a Testemunha 1 , um ganho de $723 \mathrm{~kg} \mathrm{ha}^{-1}$ ou 23,35\%. O tratamento SPM + Previnil 720 sc teve uma diferença da testemunha de $32,20 \%$ ou de $1.230 \mathrm{~kg} \mathrm{ha}^{-1}$. SPM + Manfil 800 WD diferiu cerca de $31,79 \%$, diferença de $1.207 \mathrm{~kg} \mathrm{ha}^{-1}$. SPM + Fezan
Gold obteve diferença de 31,59\%, ganho de 1.196 $\mathrm{kg} \mathrm{ha}^{-1} \cdot \mathrm{SPM}+$ Eleve obteve diferença de 31,47\%, ou seja, $1.189 \mathrm{~kg} \mathrm{ha}^{-1}$ a mais que a repetição sem controle. SPM + Nillus diferiu 28,85\%, uma produtividade superior a testemunha de $1.050 \mathrm{~kg}$ ha $^{-1}$. SPM + Bravoniln720 sc obteve diferença significativa em relação a testemunha de 27,04\%, uma diferença de $960 \mathrm{~kg} \mathrm{ha}^{-1}$.

A produtividade da soja, expressa em rendimento $\left(\mathrm{kg} \mathrm{ha}{ }^{-1}\right)$ foi reduzida em função da intensidade de P. pachyrbizi. De acordo com o experimento de Silva et al (2010), As médias de produtividade segundo a avaliação, para Ciproconazole, corroborando com este trabalho 
com a análise de variância da produtividade houve diferença significativa entre os tratamentos pelo teste de F, a 5\% de significância, e todos os tratamentos foram superiores a Testemunha.

Uma variável possível sobre a produtividade baixa da cultura nesta safra 2018-2019 se deve a falta de chuva, com 21 dias de veranico após o plantio, e na fase de enchimento de grãos mais 11 dias sem chuva. Para efeito de confirmação deve fazer a repetição do trabalho para avaliar os principais pontos analisados e a interferência climática sobre os mesmos.

\section{CONCLUSÃO}

Todos os tratamentos químicos foram superiores na redução do fungo, porém há relevância os tratamentos: SPM + Bravonil 500 SC; SPM + Unizeb Gold e SPM + Previnil 720 sc, com relação a curva AACPD.

Os tratamentos SPM + Difere, SPM + Previnil 720, SPM + Manfil 800 WD, SPM + Fezan Gold, SPM + Eleve, SPM + Nillus, SPM + Bravonil 720 SC apresentaram os melhores resultados para a produtividade de grãos na cultura.

A mistura de fungicidas protetores com fungicidas sistêmicos aumenta o modo de ação desses produtos, diminuindo assim a chance desses patógenos se tornarem resistente.

\section{REFERÊNCIAS}

ALEXANDRE DINNYS ROESE1: OSCAR FONTÃO DE LIMA FILHO2. Efeito de fungicidas no controle da ferrugem da soja, na produtividade e nos teores nutricionais em folhas e grãos. Embrapa Agropecuária oeste 2010 .

ALVES, V.M.; JULIATTI, F.C. Fungicidas no manejo da ferrugem da soja, processos fisiológicos e produtividade da cultura. Summa Phytopathologica, v.44, n.3, p.245-251, 2018.

CANTERI, M. G.; GODOY, C. V. Escala diagramática para avaliação da severidade da ferrugem da soja. Summa
Phytopathologica, Botucatu, v. 29, n. 1, p. 89, jan./mar. 2003.

CARLIN, V.J.1; SZTOLTZ, J.1; MAINARDI, J.T.1; SOUZA, R.1; SILVESTRI, M.D.B.1; NETTO, M.A.1. Ensaio de rede - avaliação de fungicidas multissítios no controle da ferrugem-asiática da soja (phakopsora pachyrhizi) na safra 2018/2019 em diamantino-mt.p. 142-145. (Resumo)

DYNNYS, R. A; FILHO, L. F. O. Efeito de fungicidas no controle da ferrugem da soja, na produtividade e nos teores nutricionais em folhas e grãos. Dourados, Mg. n.1, Agosto. 2010.

ELEVAGRO. (2015). Fungicidas sistêmicos: benzimidazóis, triazóis e estrobilurinas.

Disponível em: <HTTPS://ELEVAGRO.COM/MATERI AIS DIDATICOS/FUNGICIDASSISTEMICOS-BENZIMIDAZOISTRIAZOIS-E-ESTROBILURINAS/> Acessado em 13 de dezembro. 2019.

ELEVAGRO. (2017). Mecanismo e modo de ação do grupo químico das carboxamidas. Disponível em:

<https://elevagro.com/detalhes/mecanis mo-e-modo-de-acao-do-grupo-quimicodas-carboxamidas $/>$ Acessado em 13 de dezembro. 2019.

HARTMAN, G.L.; MILES, M.R.; FREDERICK, R.D. 2005. Breeding for resistance to soybean rust. Plant Disease 89: 664-666.

\section{JACQUELINE FRANÇA DA SILVA1; FERNANDO CEZAR JULIATTI2; ANAKELY ALVES REZENDE1. Diferentes épocas de aplicação de azoxistrobina + ciproconazole seguida de ciproconazole no controle da ferrugem asiática. Biosci. J., Uberlândia, v. 26, n. 2, p. 216-225, Mar./Apr. 2010.}

NOTÍCIAS AGRÍCOLAS.(2016). Fungicidas protetores se destacam entre as ferramentas de controle da ferrugem asiática na soja. Disponível em: <http://uplbrasil.com.br/fungicidasprotetores-se-destacam-entre-asferramentas-de-controle-da-ferrugemasiatica-na-soja/> Acessado em: 13 jun. 2019.

SHANER, G. \& FINNEY, R.E. The effect of 
nitrogen fertilization on the expression of slowmildewing resistance in knox wheat. Phytopathology 70:1183-1186. 1977.

SILVA, F. de AS. ASSISTAT: Versão 7.7 beta. Campina Grande: Universidade Federal de Campina Grande. Centro de Tecnologia e Recursos Naturais. Departamento de Engenharia Agrícola, 2016.

SILVA, J. F.; REZENDE, A. A.; JULIATTI, F. C. Diferentes épocas de aplicação de azoxistrobina + ciproconazole seguida de ciproconazole no controle da ferrugem asiática. 2010.

UPL BRASIL. (2017). O que são Multissítios?
Disponível em: < $\underline{\text { http://uplbrasil.com.br/o- }}$ que-sao-multissitios $/>$ Acessado em 13 de dezembro. 2019.

VITTI, A.J.; PAIVA, S.B.; CASTRRO, R.M.; VEIGA, J.S.; GARCIA, L. Efeito residual e curativo de fungicidas para o controle de ferrugem da soja (Phakopsora pachyrhizi). Fitopatologia Brasileira, Brasília, v.29, Supl. p.290, 2004. (Resumo)

YORINORI, J.T. A ferrugem "asiática" da soja no continente americano: evolução, importância econômica e estratégias de controle. In: JULIATTI, A.C.; POLIZEL, A.C.; HAMAWAKI, O.T.I Workshop brasileiro sobre a ferrugem asiática. Uberlândia: EDUFU, 2005. Chap. 2, p. 21-37. 